\title{
Interferon- $\alpha$ gene therapy for cancer: retroviral transduction of fibroblasts and particle-mediated transfection of tumor cells are both effective strategies for gene delivery in murine tumor models
}

\author{
T Tüting ${ }^{1}$, A Gambotto ${ }^{2}$, J Baar ${ }^{1}$, ID Davis ${ }^{1}$, WJ Storkus ${ }^{1,2,3}$, PJ Zavodny ${ }^{4}$, S Narula ${ }^{4}$, H Tahara ${ }^{1}$, \\ PD Robbins ${ }^{2}$ and MT Lotze ${ }^{1,2}$ \\ ${ }^{1}$ Departments of Surgery, ${ }^{2}$ Molecular Genetics and Biochemistry, and ${ }^{3}$ Pathology, University of Pittsburgh School of Medicine, and \\ University of Pittsburgh Cancer Institute, Pittsburgh, PA; ${ }^{4}$ Schering-Plough Research Institute, Kenilworth, NJ, USA
}

\begin{abstract}
Stable transfection of tumor cells with IFN- $\alpha$ genes has been shown to result in abrogation of tumor establishment and induction of antitumor immunity. However, strategies suitable for the clinical application of IFN- $\alpha$ gene therapy for cancer have not been reported. In this study, we investigated two gene delivery systems capable of mediating the local paracrine production of high levels of biologically active IFN- $\alpha$ in murine tumor models: retroviral transduction of fibroblasts and particle-mediated transfection of tumor cells. In spite of the antiproliferative effects of IFN$\alpha$, it was possible to obtain stable retroviral producer cell lines and transduce a variety of murine tumor cells including syngeneic fibroblasts to stably secrete 2000-5000 U (40-100 ng) murine IFN- $\alpha / 10^{6}$ cells/24 h. IFN- $\alpha$ transduction of tumor cells abrogated tumorigenicity in establishment models and induced antitumor immunity in several murine tumor model systems. Importantly, IFN- $\alpha$ gene
\end{abstract}

delivery using retrovirally transduced syngeneic fibroblasts was capable of suppressing the establishment of the poorly immunogenic TS/A mouse mammary adenocarcinoma and induced antitumor immunity. Particle-mediated transient transfection of tumor cells using the gene gun led to the production of up to $20000 \mathrm{U}$ IFN- $\alpha / 10^{6}$ cells during the first $24 \mathrm{~h}$ and proved to be equally effective in suppressing establishment of TS/A adenocarcinoma and inducing antitumor immunity. These results suggest that retroviral transduction of autologous fibroblasts can serve as an effective gene delivery method for IFN- $\alpha$ gene therapy of cancer. Particle-mediated transfection of freshly isolated tumor cells may represent a clinically attractive alternative approach for nonviral gene delivery. Both strategies circumvent the difficulties in routinely establishing primary tumor cell lines from the vast majority of human cancers.

Keywords: cytokines; interferon- $\alpha$; gene therapy; cancer; retroviral vector; particle-mediated gene transfer

\section{Introduction}

Cancer vaccines consisting of tumor cells genetically engineered to secrete immunostimulatory cytokines such as GM-CSF, IL-2, IL-4 or IL-12 have been shown to induce antitumor immune responses in several murine tumor models. ${ }^{1-3}$ Although interferon- $\alpha$ (IFN- $\alpha$ ) was the first cytokine used effectively in clinical trials with cancer patients and is approved for the treatment of several human malignancies, its use in antitumor cytokine gene therapy has not been extensively developed. ${ }^{4}$ In preclinical models, a marked loss of tumorigenicity of tumor cell clones stably transfected with expression plasmids containing IFN- $\alpha$ genes was observed in several murine tumor models. ${ }^{5-9}$ Rejection of IFN- $\alpha$-transduced tumor cells resulted in the induction of a long-lasting tumorspecific immunity against unmodified parental tumor

Correspondence: MT Lotze, Department of Surgery, University of Pittsburgh School of Medicine, Biomedical Science Tower, W1540, 200 Lothrop Street, Pittsburgh, PA 15261, USA

Received 2 May 1997; accepted 11 June 1997 cells in immunocompetent animals. In the TS/A mouse mammary adenocarcinoma, a poorly immunogenic model, this effect was totally dependent on $\mathrm{CD}^{+} \mathrm{T}$ lymphocytes ${ }^{6}$ indicating that vaccination with IFN- $\alpha$-transduced tumor cells is able to promote the induction of tumor-specific CTL responses.

IFN- $\alpha$ is a cytokine secreted by antigen-presenting cells, in particular by macrophages and dendritic cells, ${ }^{10-13}$ during the early phase of viral and bacterial infections. It has important immunoregulatory functions in addition to its antiviral effects. IFN- $\alpha$ causes macrophage differentiation, enhances the generation and increases the cytotoxicity of NK cells and $\mathrm{CD}^{+}$cytotoxic $\mathrm{T}$ lymphocytes, and favors the generation of type $1 \mathrm{~T}$ helper cells. ${ }^{14,15}$ IFN- $\alpha$ has been shown to induce the expression of the IL12 receptor $\beta 2$ subunit, which is selectively expressed by human Th1 cells. ${ }^{15}$ Interestingly, type I interferons have also been found to cause $T$ cell receptor-independent proliferation of memory CD8 ${ }^{+} \mathrm{T}$ cells. ${ }^{16} \mathrm{IFN}-\alpha$ also has direct effects on tumor cells. It increases the expression of MHC class I molecules, leading to enhanced immune recognition. Furthermore, it down-regulates the expression of 
oncoproteins and induces the expression of tumor suppressor genes which contribute to its antiproliferative actions. ${ }^{17-19}$

Clinical application of cytokine gene-engineered tumor cells as cancer vaccines has been problematic, in part because of the difficulty in routinely establishing primary tumor cell lines from the vast majority of human cancers. Most current clinical studies employ autologous tumor cells retrovirally transduced with cytokine genes, ${ }^{20}$ which can only be obtained in a subset of the patients after several weeks of culture. Some investigators have therefore resorted to standardized and well-characterized allogeneic tumor cell lines retrovirally transduced with cytokine genes, which are readily available. Another possibility is to use autologous fibroblasts for gene delivery, ${ }^{21,22}$ which can be easily obtained and cultured from virtually all individuals. Once in culture, replicating fibroblasts can be transduced with retroviral vectors, and expanded to sufficient numbers for therapeutic purposes. ${ }^{23,24}$ High levels of the cytokine of interest are expressed following selection for antibiotic resistance. Here, we demonstrate the applicability of this strategy for IFN- $\alpha$ gene delivery. Retroviral vectors were constructed on the basis of the MFG backbone. ${ }^{21}$ Retroviral producer cell lines could be generated, which secreted infectious viral particles, in spite of anticipated problems due to the inherent antiviral and antiproliferative effects of IFN- $\alpha$. Tumor cells as well as syngeneic murine fibroblasts could be retrovirally transduced, selected for antibiotic resistance, and quickly expanded, resulting in stable secretion of biologically active IFN- $\alpha$, suppression of tumor establishment in vivo and induction of antitumor immunity.

An alternative strategy has been the use of particlemediated gene delivery of plasmid expression vectors encoding cytokine genes into freshly isolated tumor cell suspensions, resulting in transient high-level expression which may obviate the need for viral vectors and lengthy in vitro culture periods to allow for selection of stably transduced cells. ${ }^{25-28}$ This technology now utilizes a helium-driven, hand-held 'gene gun' (Accell) which propels DNA-coated microparticles into cells or tissues. We show here that this strategy can also effectively deliver IFN- $\alpha$ genes in vivo, capable of mediating its antitumor effects.

\section{Results}

\section{Expression of biologically active IFN- $\alpha$}

The plasmids pCMV-A-mIFN $\alpha 2$, pCMV-A-hIFN $\alpha 2 / 1$, DFG-mIFN $\alpha 2$-neo and DFG-hIFN $\alpha 2 / 1$-neo (Figure 1) were constructed as described in Materials and methods and tested for production of biologically active IFN- $\alpha$. 293 Cells were transiently transfected using standard calcium phosphate precipitation. Supernatants were harvested after $48 \mathrm{~h}$ and assayed by ELISA. Both CMV-Abased expression plasmids induced the production of 10 000-15000 U IFN- $\alpha / 10^{6}$ cells $/ 48 \mathrm{~h}$, whereas the MFGbased vectors induced the production of $100 \mathrm{U}$ IFN- $\alpha / 10^{6}$ cells $/ 48 \mathrm{~h}$ reflecting the relative inefficiency of the retroviral LTR when used as an expression plasmid. To ascertain the biologic activity of transgene products a viral cytopathic effect inhibition assay including antibody neutralization was performed as detailed in Materials and methods. These assays confirmed production levels of bioactivate IFN- $\alpha$ corresponding to levels of immunoreactive IFN- $\alpha$ measured by ELISA.

\section{Preparation of retroviral producer cell lines}

Ecotropic retroviral supernatant was generated by transient transfection of DFG-mIFN $\alpha 2$-neo and DFGhIFN $\alpha 2 / 1$-neo into BOSC23 using standard calcium phosphate transfection in the presence of chloroquine. ${ }^{29}$ Stable amphotropic retroviral producer cell lines were generated by infection of CRIP cells ${ }^{30}$ with BOSC23derived ecotropic viral supernatant. Supernatants of CRIP-DFG-mIFN $\alpha 2$-neo and CRIP-DFG-hIFN $\alpha 2 / 1-$ neo contained bioactive $\mathrm{mIFN} \alpha 2$ and hIFN $\alpha 2 / 1$ respectively, indicating that infectious retroviral particles carrying the IFN- $\alpha$ genes had been produced by the transfected BOSC23 cells. Thus, the inherent antiviral effects of IFN$\alpha$ did not negatively impact on the ability to generate retroviral vectors and stable producer cell lines.

\section{Retroviral or particle-mediated IFN- $\alpha$ gene delivery to murine tumor cells and fibroblasts}

A series of murine tumor cell lines as well as two embryonic fibroblast lines were stably transduced with CRIPDFG-mIFN $\alpha 2$-neo supernatant. Cells were incubated with viral supernatant containing polybrene $(8 \mu \mathrm{g} / \mathrm{ml})$ at $37^{\circ} \mathrm{C}$. The culture medium was replaced after $3 \mathrm{~h}$ and antibiotic selection applied after $48 \mathrm{~h}(0.75 \mathrm{mg} / \mathrm{ml} \mathrm{G} 418)$. Ten to 14 days later, production of mIFN- $\alpha 2$ by the selected tumor cells was measured by ELISA (Table 1) and biological activity confirmed by viral cytopathic effect inhibition assay. Furthermore, IFN- $\alpha$-transduced cell lines displayed increased surface expression of MHC class I molecules demonstrating its intrinsic biological effects (Table 2). Alternatively, we performed in vitro particle-mediated gene delivery to tumor cell suspensions using pCMV-A-mIFN $\alpha 2$ after optimization of transfection parameters. Production of $\operatorname{mIFN}-\alpha 2$ by $10^{6}$ tumor cells / $24 \mathrm{~h}$ was again assessed by ELISA (Table 1) and biological activity confirmed. Transient particle-mediated transfection resulted in significantly higher production of IFN- $\alpha$ during the first $48 \mathrm{~h}$ compared with stable retroviral transduction. Because of the transient nature of particle-mediated gene delivery we followed the time-course of cytokine production using irradiated TS/A tumor cells stably transduced with DFG-mIFN $\alpha 2-n e o$ or transiently with pCMV-A-mIFN $\alpha 2$ using the gene gun. Particlemediated transduction resulted in much higher levels of mIFN- $\alpha 2$ production during the first $24-48 \mathrm{~h}$ compared with stable retroviral transduction but dropped sharply thereafter (Figure 2).

\section{Stable transduction with IFN- $\alpha$ abrogates tumorigenicity and induces antitumor immunity in two mouse tumor models}

The tumorigenicity of TS/A and MC38 tumor cells stably transduced with DFG-mIFN $\alpha 2-$ neo was tested in vivo. Both parental tumor cell lines are poorly immunogenic and $10^{5}$ cells injected subcutaneously (s.c.) consistently grow and kill their host. Transduction with IFN- $\alpha$ did not alter their in vitro growth characteristics (data not shown). However, $10^{5}$ TS/A-mIFN $\alpha 2$ or MC38-mIFN $\alpha 2$ cells injected s.c. did not establish tumors (Figure 3). Thus, stable transduction of TS/A and MC38 adenocarcinoma with DFG-mIFN $\alpha 2$-neo abrogated tumorigenicity. 

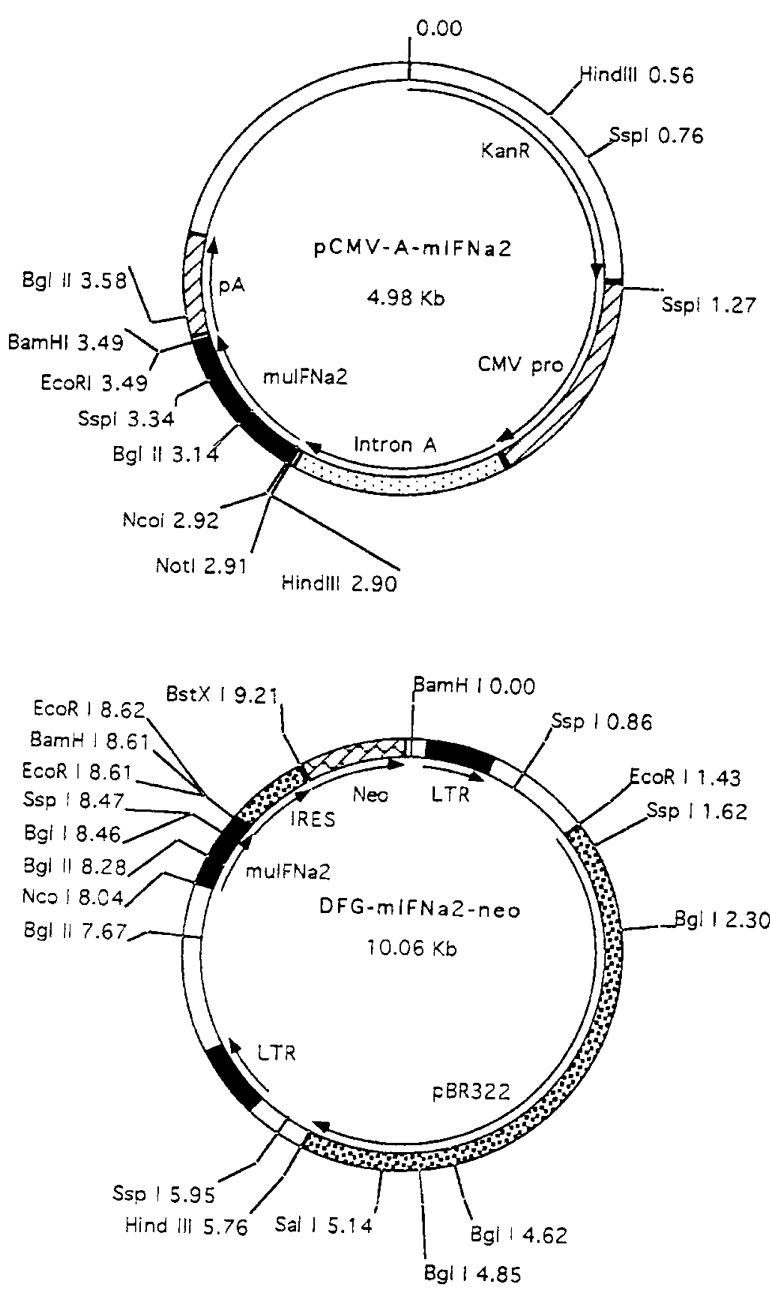

Figure 1 Schematic diagrams of vectors used in this study. Details of construction are outlined in Materials and methods.

Table 1 Production of murine IFN- $\alpha 2$ after in vitro transduction

Cell line $\begin{gathered}\text { Gene gun } \\ \text { transfection } U\end{gathered} \quad \begin{gathered}\text { Retroviral } \\ \text { transduction } U\end{gathered}$

\begin{tabular}{lrr}
\hline B16 & 8200 & 4000 \\
TS/A & 20000 & 3200 \\
MC38 & 12000 & 2400 \\
MCA205 & 15000 & 5000 \\
TIB80 & 2000 & 4000 \\
TIB81 & 1500 & 1000
\end{tabular}

$10^{6}$ Cells retrovirally transduced with DFG-mIFN $\alpha 2$ or gene gun transfected with pCMV-A-mIFN $\alpha 2$ were seeded into $75 \mathrm{~cm}^{2}$ flasks. Supernatants were harvested after $24 \mathrm{~h}$ and mIFN- $\alpha 2$ measured by ELISA. Results are presented as U/ $10^{6}$ cells $/ 24 \mathrm{~h}$ (1 U approximately equals $20 \mathrm{pg}$ ).

In order to assess the induction of a long-lasting antitumor immune response, animals that had rejected TS/A-mIFN $\alpha 2$ or MC38-mIFN $\alpha 2$ were challenged with $3 \times 10^{5}$ wild-type TS/A or MC38, respectively, 6 weeks after the initial tumor challenge. All animals resisted this rechallenge in both groups, whereas naïve animals developed large tumors within 14 days (data not shown).
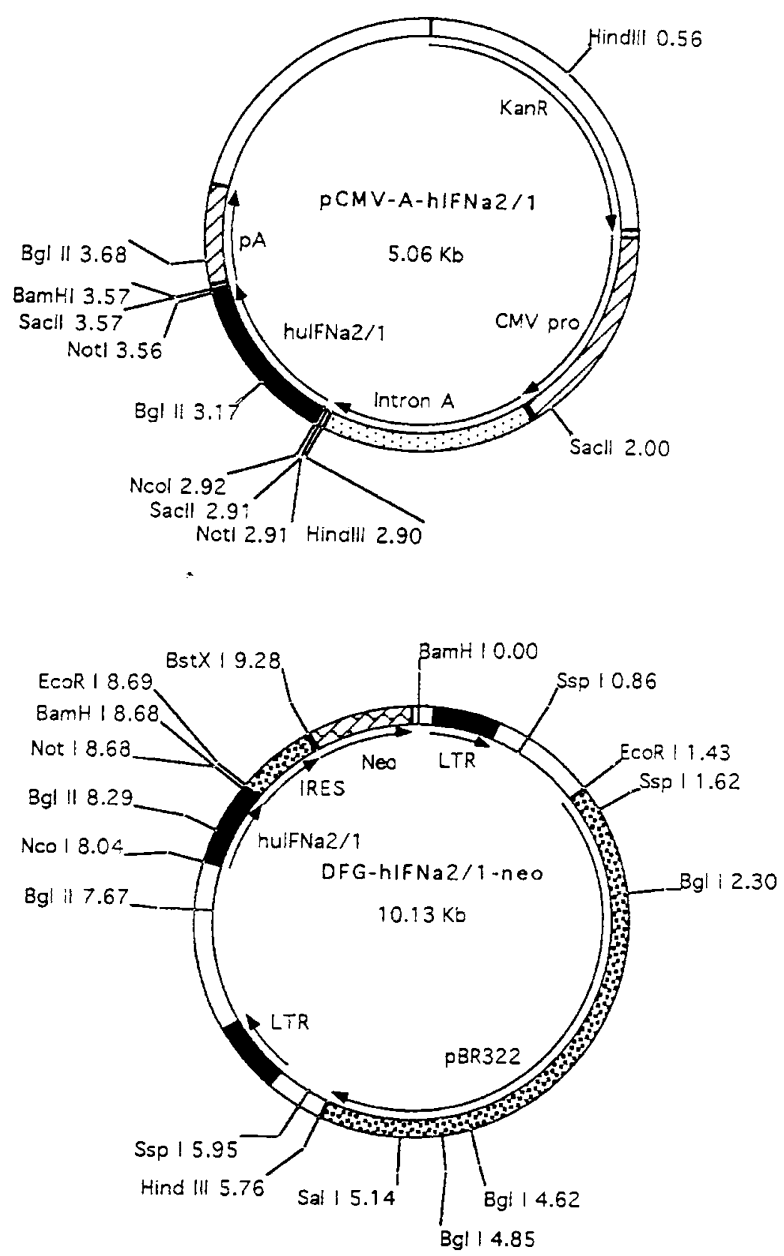
mediated transient transfection of tumor cells are equally effective for IFN- $\alpha$ gene delivery in vivo

Next, IFN- $\alpha$ gene delivery was tested using the embryonic fibroblast line TIB80 retrovirally transduced with DFG-mIFN $\alpha 2$-neo. $10^{6}$ TIB80-mIFN $\alpha 2$ producing $5000 \mathrm{U}$ mIFN- $\alpha / 10^{6}$ cells $/ 24$ h or $10^{6}$ wild-type TIB 80 as controls were admixed with $10^{5}$ wild-type TS/A tumor cells and injected s.c. Paracrine secretion of IFN- $\alpha$ precluded establishment of TS/A tumor cells (Figure 4). Animals that had rejected TS/A due to paracrine secretion of $\mathrm{mIFN} \alpha 2$, were challenged with $3 \times 10^{5}$ wild-type TS/A 6 weeks after the initial tumor challenge. All animals resisted this rechallenge indicating the induction of antitumor immunity.

Alternatively, IFN- $\alpha$ gene delivery using particlemediated transient transfection of irradiated tumor cells was investigated. $10^{6} \mathrm{TS} / \mathrm{A}$ tumor cells were transfected with either pCMV-A-mIFN $\alpha 2$ or pCMV-A as control, irradiated (100 Gy), admixed with $10^{5}$ wild-type TS/A tumor cells, and injected s.c. Again, local production of IFN- $\alpha$ abrogated tumor establishment (Figure 4) and led to the induction of antitumor immunity as assessed by rechallenge and rejection of $3 \times 10^{5}$ TS/A tumor cells. Thus, both methods are capable of efficiently delivering IFN- $\alpha$ gene therapy in vivo. 
Table 2 Up-regulation of MHC class I expression after in vitro transduction with $\mathrm{mIFN} \alpha 2$

\begin{tabular}{lcccccr}
\hline Cell line & Wild type & MFG-neo & DFG-mIFN $\alpha 2$ & CMV-A & CMV-A-muIFN 22 & $1000 U / m l r m I F N \alpha 2$ \\
\hline B16 & 6 & 7 & 25 & 6 & 29 & 22 \\
TS/A & 38 & 45 & 104 & 41 & 89 & 98 \\
MC38 & 118 & 124 & 267 & 131 & 286 & 254 \\
MCA205 & 21 & 16 & 50 & 17 & 61 & 48 \\
\hline
\end{tabular}

Cells were stained with anti-K $\mathrm{K}^{\mathrm{d}}$ (TS/A), anti-K $\mathrm{K}^{\mathrm{b}}$ (MC38, MCA205) or anti-D ${ }^{\mathrm{b}}$ (B16) mAb following retroviral transduction with DFG$\mathrm{mIFN} \alpha 2$, gene gun transfection with pCMV-A-mIFN $\alpha 2$ or treatment with recombinant mIFN- $\alpha 2$. Results are presented as mean fluorescence intensity.

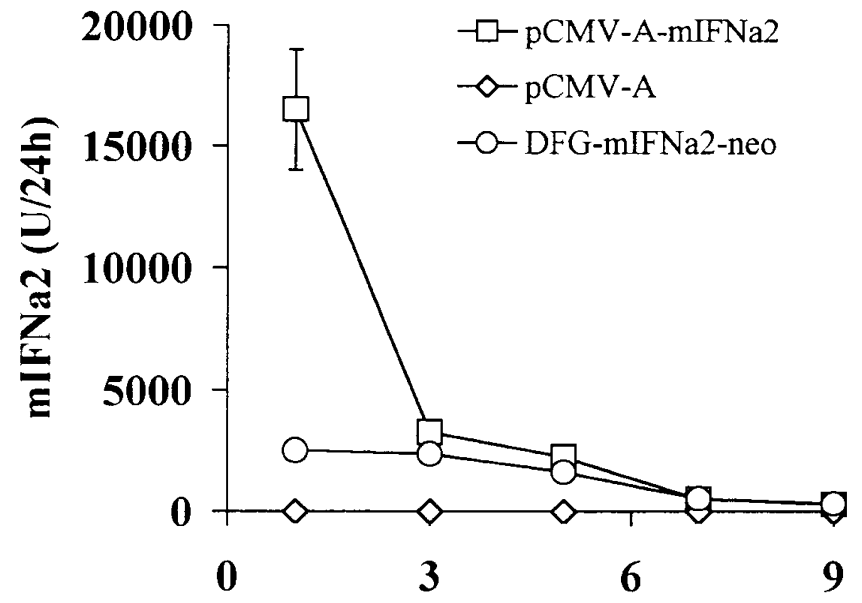

Days post transfection

Figure 2 In vitro IFN- $\alpha$ production by TS/A tumor cells transiently transfected by particle bombardment or stably transduced using a retroviral vector. $10^{6} \mathrm{TS} / \mathrm{A}$ tumor cells transiently transfected with the expression plasmid $p C M V$-mIFN $\alpha 2$ or $10^{6}$ TS/A tumor cells stably transduced with DFG-mIFN 2-neo were irradiated (10000 rad) and seeded into $75 \mathrm{~cm}^{2}$ flasks in $10 \mathrm{ml}$ of complete medium. Medium was replaced at the indicated time-points and assayed for mIFN- $\alpha 2$ content by ELISA Production levels were calculated as $U / 24 h$ (1 $U$ approximately equals $50 \mathrm{pg}$ ). $\mathrm{pCMV}-\mathrm{A}$ is the backbone plasmid.

\section{Retroviral or particle-mediated IFN $\alpha$ gene delivery to human tumor cells}

To assess the possible clinical application of IFN- $\alpha$ gene therapy, two established human melanoma cells were stably transduced with CRIP-DFG-hIFN $\alpha 2 / 1$-neo. Production of hIFN $\alpha 2 / 1$ by $10^{6}$ cells $/ 24 \mathrm{~h}$ was verified by ELISA (Table 3). IFN- $\alpha$-transduced cell lines also displayed increased surface expression of MHC class I molecules demonstrating its biological effects (Table 4). Alternatively, in vitro particle-mediated gene delivery to tumor cell suspensions was performed. High production of hIFN $\alpha 2 / 1$ by $10^{6}$ cells $/ 24 \mathrm{~h}$ was shown by ELISA using optimized transfection parameters (Table 3) which again resulted in increased surface expression of MHC class I molecules (Table 4). In two preliminary experiments, single cell suspensions prepared from freshly excised melanoma metastases were transfected by particle bombardment; in both cases, significant, although five-fold lower amounts of hIFN $22 / 1$ were produced. These studies confirmed the applicability of this approach for human tumor cells in vitro.

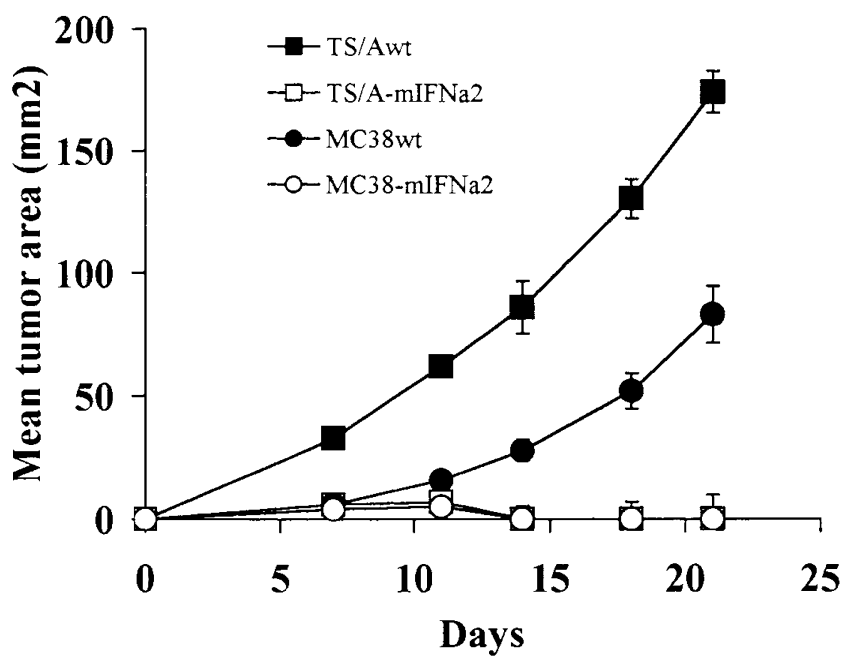

Figure 3 Establishment of the poorly immunogenic murine adenocarcinomas TS/A and MC38 is abrogated following stable retroviral transduction with DFG-mIFN- $\alpha 2-n e o .10^{5}$ MC38 or TS/A tumor cells transduced with DFG-mIFN- $\alpha 2-n e o$, as well as $10^{5}$ wild-type MC38 or TS/A tumor cells, were injected s.c. in the flank of syngeneic $(C 57 B l / 6$ or $B A L B / c)$ mice and tumor growth monitored. Results are reported as mean tumor area ( \pm s.e.m.).

\section{Discussion}

Several groups have observed that stable transfection of mouse tumor cell lines with IFN- $\alpha$ expression plasmids abrogates tumorigenicity in vivo. ${ }^{5-9}$ Here, we report the construction of retroviral vectors and the preparation of retroviral producer cell lines for IFN- $\alpha$ gene therapy of cancer and confirm their applicability and efficacy in murine tumor models. Retroviral transduction of two poorly immunogenic mouse tumor cell lines (MC38 colon adenocarcinoma and TS/A mammary adenocarcinoma) prevents tumor establishment and induces tumor-specific immunity. Importantly, we show that syngeneic fibroblasts can efficiently be retrovirally transduced to secrete IFN- $\alpha$ stably. Coinjection of IFN- $\alpha$-transduced fibroblasts with wild-type TS/A suppresses tumor establishment and leads to the induction of tumor-specific immunity, indicating effective local delivery of biologically active IFN- $\alpha$ by genetically engineered fibroblasts in vivo. We have previously successfully implemented this fibroblast delivery-based strategy for both IL-4 and IL-12 gene therapy of cancer ${ }^{23,24}$ and are currently entering phase II clinical trials with the latter. A similar strategy may now be envisioned for IFN- $\alpha$ gene therapy of cancer. 


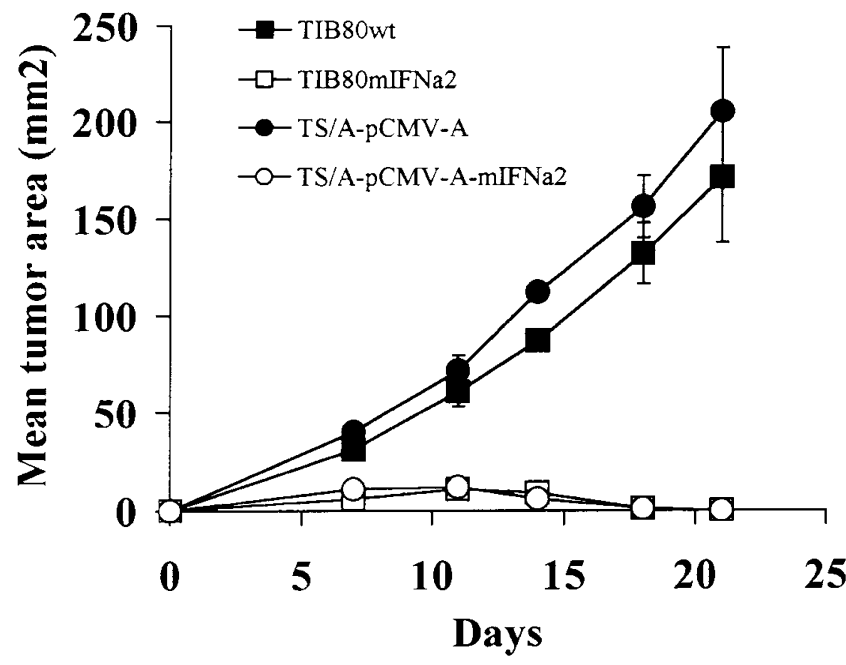

Figure 4 IFN- $\alpha$ gene delivery using retrovirally transduced fibroblasts, as well as particle-mediated transient transfection of tumor cells are capable of suppressing establishment of the poorly immunogenic murine mammary adenocarcinoma TS/A. $10^{6}$ Syngeneic TIB80 fibroblasts retrovirally transduced with DFG-mIFN- $\alpha 2-n e o$ or $10^{6}$ wild-type TIB80 fibroblasts as controls were admixed with $10^{5}$ wild-type TS/A tumor cells, injected s.c. in the flank of BALB/c mice, and tumor growth recorded. Alternatively, $10^{6}$ irradiated (10000 rad) TS/A tumor cells were transiently transfected in suspension with $p C M V-m I F N \alpha 2$ or with $p C M V-A$ as control by particle bombardment, admixed with $10^{5}$ wild-type TS/A tumor cells, and injected s.c. in the flank of $B A L B / c$ mice. Results are reported as mean tumor area ( \pm s.e.m.).

Table 3 Production of huIFN- $\alpha$ after in vitro transduction

\begin{tabular}{|c|c|c|c|}
\hline Cell line & $D F G-h u I F N \alpha 2 / 1$ & $C M V-A U$ & $C M V-A-h u I F N \alpha 2 / 1$ \\
\hline Mel 526 & 10000 & 0 & 12000 \\
\hline Mel 624 & 8000 & 0 & 10000 \\
\hline
\end{tabular}

$10^{6}$ cells retrovirally transduced with DFG-hIFN $\alpha 2 / 1$ or gene gun transfected with pCMV-A-hIFN $\alpha 2 / 1$ were seeded into $75 \mathrm{~cm}^{2}$ flasks. Supernatants were harvested after $24 \mathrm{~h}$ and human IFN- $\alpha$ measured by ELISA. Results are presented as $\mathrm{U} / 10^{6}$ cells $/ 24 \mathrm{~h}$ ( $1 \mathrm{U}$ approximately equals $20 \mathrm{pg}$ ).

As an alternative to virus-mediated gene transfer, we explored the feasibility of delivering IFN- $\alpha$ genes by transiently transfecting tumor cell suspensions using particlemediated gene transfer technology. Following particle bombardment with IFN- $\alpha$ expression plasmids incorporating strong CMV-IntronA-driven promoters, both murine and human engineered tumor cells transiently produced large amounts of IFN- $\alpha$. Particle bombardment initially led to the production of higher levels of IFN- $\alpha$ which fell to levels comparable to those produced by irradiated, retrovirally transduced tumor cells after several days. As expected, paracrine secretion of IFN- $\alpha$ following ex vivo gene gun transfection of irradiated TS/A tumor cells suppressed the establishment of coinjected wild-type TS/A tumor cells, demonstrating effective, therapeutic gene delivery in vivo.

Other investigators have vaccinated mice with irradiated melanoma cells genetically modified ex vivo to express GM-CSF with a similar particle-mediated gene transfer strategy resulting in protective antitumor immunity. ${ }^{27}$ A clinical protocol is being proposed, where freshly isolated human melanoma cell suspensions are transfected with GM-CSF using the 'gene gun' and applied as a therapeutic vaccine for patients with metastatic melanoma. We have confirmed the feasibility of transfecting single cell suspensions prepared by digestion of freshly explanted melanoma metastases using our IFN$\alpha$ expression plasmids. This might represent a clinically attractive alternative approach to protocols using viral delivery systems designed to implement IFN- $\alpha$ gene therapy for cancer.

Vaccines consisting of freshly digested tumor cell suspensions transduced ex vivo with cytokine cDNA are also being developed using receptor-mediated endocytosis of molecular protein/plasmid DNA conjugates $^{31}$ or viral vectors $^{32}$ as transfection modalities. Alternatively, cytokine genes may be delivered directly into the tumor. The major hurdle of such in vivo gene delivery has been the comparatively low expression level of transgenes. Recently, novel adenovirus, adeno-associated virus, and vaccinia virus vectors encoding IFN- $\alpha, 33,34$ IL-2, ${ }^{35} \mathrm{GM}-$ $\mathrm{CSF}^{36}$ or IL-12 ${ }^{37-40}$ have demonstrated therapeutic utility following direct intratumoral injection in animal models. The inherent immunogenicity of viral vectors, as well as potential safety concerns may, however, limit their applicability in humans. These new methods will have to be compared with existing strategies for cytokine gene therapy before intelligent choices may be made.

Also, gene therapies incorporating IFN- $\alpha$ in combination with suicide genes or genes encoding costimulatory molecules such as B7.1 will have to be investigated given the presumed synergistic action of such strategies. Using interferon-insensitive Friend leukemia cells in a day 3 treatment model, perilesional injection of tumor cells transduced with both IFN- $\alpha$ and the suicide gene herpes simplex virus thymidine kinase followed by administration of ganciclovir (starting on day 7) were able to cure established tumors and induce a long-lasting immune response. ${ }^{9}$ In preliminary experiments we observed enhanced antitumor immune responses using

Table 4 Up-regulation of MHC class I expression after in vitro transduction with hIFN $\alpha$

\begin{tabular}{|c|c|c|c|c|c|}
\hline Cell line & Wild type & $D F G-h I F N \alpha 2 / 1$ & $C M V-A$ & $C M V-A-h I F N \alpha 2 / 1$ & $1000 \mathrm{U} / \mathrm{ml} \mathrm{rhIFN} \alpha 2 / 1$ \\
\hline Mel526 & 124 & 241 & 118 & 298 & 302 \\
\hline Mel624 & 95 & 176 & 102 & 243 & 241 \\
\hline
\end{tabular}

Tumor cells were stained with w6/32 mAb following retroviral transduction with DFG-huIFN $\alpha 2 / 1$, gene gun transfection with pCMVA-huIFN $\alpha 2 / 1$ or treatment with recombinant human IFN $\alpha 2 / 1$. Results are presented as mean fluorescence intensity. 
IFN- $\alpha$ gene therapy in combination with the costimulatory molecule gene B7.1.

In summary, we have demonstrated the feasibility of IFN- $\alpha$ gene therapy for the treatment of cancer using retrovirally transduced fibroblasts as a perilesional delivery system in vivo. We further show that particlemediated IFN- $\alpha$ gene delivery to freshly isolated tumor cell suspensions can be employed as an alternative strategy, generating an effective vaccine, which obviates the need for costly in vitro culture of patient-derived materials to be used in clinical protocols.

\section{Materials and methods}

\section{Reagents}

Natural mouse IFN- $\alpha$ produced by virally infected (NDV) mouse L929-cells was a kind gift of Dr P Whitaker-Dowling, University of Pittsburgh, Pittsburgh, PA, USA. A sheep polyclonal anti-mouse IFN- $\alpha$ antibody was a kind gift of Dr I Gresser, Institut Gustav Roussy, Paris, France. Recombinant mouse IFN $\alpha 2$ and recombinant human IFN $\alpha 2 / 1$ hybrid, a monoclonal anti-human IFN$\alpha$ antibody (clone MMHA-1; Pestka Laboratories, Rutherford, NJ, USA), a sheep polyclonal anti-human IFN- $\alpha$ antibody (Schering Plough Research Institute, Kenilworth, NJ, USA), as well as a rat monoclonal anti-mouse IFN- $\alpha$ antibody (clone 4E-A1, Seikagaku America, Rockville, MD, USA) were kindly provided by Dr Paul Zavodny (Schering Plough Research Institute).

\section{Mice}

Female BALB/cJ or C57Bl/6 mice, 6-10 weeks old, were obtained from The Jackson Laboratory (Bar Harbor, ME, USA). Animals were maintained in a specific pathogenfree facility (Central Animal Facility, University of Pittsburgh).

Cell lines

TS/A is a tumor cell line established by P Nanni (University of Bologna, Bologna, Italy) from the first in vivo transplant of a moderately differentiated mammary adenocarcinoma spontaneously arising in a 20-month-old female Balb/cnAnCr mouse and kindly provided by $\mathrm{G}$ Forni (University of Torino, Turin, Italy). Mel 526 and Mel 624, two established human melanoma cell lines, MC38, a murine colon adenocarcinoma, MCA 205, a methylcholanthrene-induced murine fibrosarcoma, and B16, a murine melanoma, were generously provided by Dr SA Rosenberg (National Cancer Institute, Bethesda, MD, USA). The embryonic fibroblast lines TIB80 and TIB81 were purchased from ATCC (Rockville, MD, USA). All cell lines were maintained in RPMI 1640 supplemented with $10 \%$ heat-inactivated FCS, 2 mM L-glutamine, $50 \mu \mathrm{M}$ Hepes, and $100 \mathrm{IU} / \mathrm{ml}$ penicillin and $100 \mu \mathrm{g} / \mathrm{ml}$ streptomycin (all reagents from GIBCO-BRL, Gaithersburg, MD, USA). BOSC23 and 293 cells were purchased from Microbix Biosystems (Toronto, Ontario, Canada) and maintained in DMEM supplemented with $10 \%$ heat-inactivated FCS, $2 \mathrm{mM}$ L-glutamine, $50 \mu \mathrm{M}$ Hepes, and $100 \mathrm{IU} / \mathrm{ml}$ penicillin, and $100 \mu \mathrm{g} / \mathrm{ml}$ streptomycin (all reagents from GIBCO-BRL).

\section{Vector construction}

Maps of pCMV-A-mIFN $\alpha 2$, pCMV-A-hIFN $\alpha 2 / 1$, DFG$\mathrm{mIFN} \alpha 2$ and DFG-hIFN $\alpha 2 / 1$ are presented in Figure 1.
The cDNAs encoding mouse IFN $\alpha 2$ and human IFN $\alpha 2 / 1$ hybrid were provided by Dr P Zavodny (Schering Plough Research Institute). An NcoI-BamHI fragment of mIFN $\alpha 2$ was generated by introducing a point mutation following the start codon and a $\mathrm{BamHI}$ restriction site immediately after the stop codon using PCR techniques. An NcoIBam HI fragment of hIFN $\alpha 2 / 1$ hybrid was generated by first digesting pUC18-hIFN $22 / 1$ with EcoRI, filling in with Klenow enzyme, BamHI oligonucleotide linkering, and then digesting with $\mathrm{NcoI}$ and BamHI. The resulting NcoI-BamHI fragments were inserted into a modified pGEM11. NotI-BamHI fragments were then inserted into p7077 (kindly provided by Agracetus, Middleton, WI, USA), a strong mammalian expression vector using the immediate-early gene promoter and the Intron A from CMV. NcoI-BamHI fragments of muIFN $\alpha 2$ and huIFN $\alpha 2 / 1$ were also inserted into the retroviral backbone termed MFG in such a way that the translational initiation codon ATG was fused to the ATG of the retroviral env gene. To obtain a retroviral construct with selectable marker an IRES-neo cassette was inserted into the BamHI site at the $3^{\prime}$ end of muIFN $\alpha 2$ and huIFN $\alpha 2 / 1$. The IRES element (a cap-independent translation enhancer from EMCV) allows the transcription of a single polycistronic message. ${ }^{41}$

\section{Particle-mediated gene delivery}

Plasmid DNA was purified using Qiagen Plasmid Maxi Kits (Qiagen, Chatsworth, CA, USA) and precipitated on to $2.6 \mu \mathrm{m}$ gold particles at a density of $2 \mu \mathrm{g}$ of DNA per milligram of particles. The DNA-particle preparation was coated on to the inner surface of Tefzel tubing using a tube loader. The tubing was cut into 0.5 inch segments resulting in the delivery of $0.5 \mathrm{mg}$ gold coated with $1 \mu \mathrm{g}$ plasmid DNA per transfection with the helium-driven Accell particle bombardment device. Gold particles, tubing, tube loader, and the Accell particle bombardment device were kindly provided by Agracetus/Geniva, Middleton, WI, USA. Tumor cells were transfected in suspension $\left(10^{6}\right.$ cells per shot) in six-well plates at a pressure of 250 p.s.i. of helium.

\section{Retroviral transduction}

For retroviral transduction $10^{6}$ cells in $75 \mathrm{~cm}^{2}$ flasks were incubated with $4 \mathrm{ml}$ of viral supernatant containing polybrene $(8 \mu \mathrm{g} / \mathrm{ml})$ at $37^{\circ} \mathrm{C}$. The culture medium was replaced after $3 \mathrm{~h}$ and antibiotic selection applied after $48 \mathrm{~h}(0.75 \mathrm{mg} / \mathrm{ml} \mathrm{G} 418)$. Stable selection was completed after 7-10 days.

\section{Viral cytopathic effect inhibition assay}

The viral cytopathic effect inhibition assay was performed using encephalomyocarditis virus (EMCV) on mouse L929 cells. Briefly, serial half-log dilutions of IFN$\alpha$ samples were performed in 96-well flat-bottomed microtiter plates and $2 \times 10^{4}$ L929 cells were added per well. Following overnight incubation at $37^{\circ} \mathrm{C}, 2 \times 10^{3}$ p.f.u. of EMCV (MOI of 0.1) were added to each well. The incubation was continued for an additional $48 \mathrm{~h}$ after which plates were washed and stained with crystal violet to observe residual viable cells. IFN activity is expressed in units $/ \mathrm{ml}$. The IFN activity was calibrated against the $\mathrm{NIH}$ reference standard for mouse IFN $-\alpha / \beta$. Antibody neutralization was performed using the sheep anti-mouse IFN- $\alpha$ polyclonal antibody. 


\section{MHC class I up-regulation}

Gene gun-transfected cells were assayed $48 \mathrm{~h}$ after transfection. Untransfected control cells were incubated with $1000 \mathrm{U}$ recombinant IFN- $\alpha$ for $48 \mathrm{~h}$. For immunophenotyping tumor cells were harvested, washed in HBSS supplemented with $1 \%$ BSA and $0.1 \% \mathrm{NaN}_{3}$, and incubated (30 $\mathrm{min}$ at $4^{\circ} \mathrm{C}$ ) with one of the following mouse monoclonal antibodies: anti-H-2K $\mathrm{K}^{\mathrm{d}}$ (HB159; ATCC), anti-H-2K $\mathrm{K}^{\mathrm{b}}$ (HB41; ATCC), anti-H-2D ${ }^{b}$ (HB14; ATCC), or anti-HLA$\mathrm{A}, \mathrm{B}, \mathrm{C}$ (w6/32; ATCC) followed by a second incubation $\left(30 \mathrm{~min}\right.$ at $\left.4^{\circ} \mathrm{C}\right)$ with a FITC-conjugated goat anti-mouse $\mathrm{F}(\mathrm{ab})_{2}$ fragment (Sigma Chemical, St Louis, MO, USA). Cells were also stained with the corresponding isotypematched control mAb. Surface expression was analyzed using a FACScan flow cytometer and Lysis II software (Becton Dickinson, Mountain View, CA, USA), data being collected on 10000 viable cells.

\section{ELISA for $m I F N \alpha 2$ and $h I F N \alpha 2 / 1$}

ELISAs were established in our laboratory using the sandwich technique as follows: 96-well microtiter ELISA plates (Dynatech Immulon 2, Chantilly, VA, USA) were coated with either the polyclonal sheep anti-mouse IFN$\alpha$ or the sheep anti-human IFN- $\alpha$ antibody at a concentration of $5 \mu \mathrm{g} / \mathrm{ml}$ in $100 \mathrm{~mm}$ sodium carbonate buffer, $\mathrm{pH} 9.5\left(16 \mathrm{~h}\right.$ at $\left.4^{\circ} \mathrm{C}\right)$. Microtiter plates were then incubated with $3 \%(\mathrm{w} / \mathrm{v})$ BSA, $0.01 \%$ Thimerosal $(\mathrm{w} / \mathrm{v})$, and $0.05 \%(\mathrm{v} / \mathrm{v})$ Tween 20 in PBS $\left(8-24 \mathrm{~h}\right.$ at $\left.4^{\circ} \mathrm{C}\right)$ to block unspecific binding followed by incubation of samples along with two-fold dilutions of recombinant mouse IFN $\alpha 2$ or recombinant human IFN $\alpha 2 / 1$ hybrid in PBS containing $1 \%(\mathrm{w} / \mathrm{v})$ BSA and $0.05 \%(\mathrm{v} / \mathrm{v})$ Tween 20 $\left(16 \mathrm{~h}\right.$ at $\left.4^{\circ} \mathrm{C}\right)$. IFN- $\alpha$ captured on microtiter plates was detected using either the monoclonal rat anti-mouse IFN$\alpha$ antibody (clone 4E-A1) or the monoclonal mouse antihuman IFN- $\alpha$ antibody (clone MMHA-1) at a concentration of $1 \mu \mathrm{g} / \mathrm{ml}$ in PBS containing $1 \%(\mathrm{w} / \mathrm{v})$ BSA and $0.05 \%(\mathrm{v} / \mathrm{v})$ Tween 20 ( $2 \mathrm{~h}$ at RT) followed by peroxidaseconjugated monoclonal goat anti-rat or goat anti-mouse IgG antibody (Sigma Chemical) at a dilution of 1:20000 in PBS containing $1 \%(\mathrm{w} / \mathrm{v})$ BSA and $0.05 \%(\mathrm{v} / \mathrm{v})$ Tween $20(1 \mathrm{~h}$ at RT). Washings with $0.05 \%(\mathrm{v} / \mathrm{v})$ Tween 20 in PBS were performed between all steps. TMB microwell peroxidase substrate system $(100 \mu \mathrm{l})$ (Kierkegaard and Perry, Gaithersburg, MD, USA) was added for color development. The reaction was stopped with $100 \mu \mathrm{l} 1 \mathrm{~N}$ $\mathrm{H}_{2} \mathrm{SO}_{4}$ and plates read at $450 \mathrm{~nm}$ with a Dynatech MR500 ELISA plate reader. The limit of detection of these ELISAs was $1 \mathrm{U} / \mathrm{ml}$ ( $1 \mathrm{U}$ approximately equals $20 \mathrm{pg}$ ).

\section{Murine studies}

Mice used in the experiments were ear-tagged and randomized before inoculation with tumor. Tumor cells were inoculated intradermally in the shaved area of the left flank, and tumor establishment was determined by palpation. Tumor size was determined by measuring perpendicular tumor diameters with a vernier caliper. All measurements were done in a coded, blinded fashion. Treatment groups consisted of five mice per group. Results are reported as mean tumor area $\left(\mathrm{mm}^{2}\right) \pm$ s.e.m.

\section{Statistical analyses}

Fisher's exact method or the Student's $t$ test were performed to interpret the significance of differences between experimental groups (presented as mean \pm s.e.m.).

\section{Acknowledgements}

This work was supported in part by a fellowship from the Deutsche Forschungs Gemeinschaft to Thomas Tüting, and contracted research from Schering Plough. We are indebted to the technicians of the Central Animal Facility of the Biomedical Science Tower for their assistance in the performance of these studies. The care and use of mice was in accordance with the guidelines of the University of Pittsburgh.

\section{References}

1 Tepper RI, Mule JJ. Experimental and clinical studies of cytokine gene-modified tumor cells. Hum Gene Ther 1994; 5: 153-164.

2 Pardoll DM. Paracrine cytokine adjuvants in cancer immunotherapy. Annu Rev Immunol 1995; 13: 399-415.

3 Tahara $\mathrm{H}$ et al. Effective eradication of established murine tumors with IL-12 gene therapy using a polycistronic retroviral vector. J Immunol 1995; 154: 6466-6474.

4 Belardelli F, Gresser I. The neglected role of type I interferon in $\mathrm{T}$ cell response: implications for its clinical use. Immunol Today 1996; 17: 369-372.

5 Ferrantini $\mathrm{M}$ et al. $\alpha 1$-Interferon gene transfer into metastatic friend leukemia cells abrogated tumorigenicity in immunocompetent mice: antitumor therapy by means of interferon-producing cells. Cancer Res 1993; 53: 1107-1112.

6 Ferrantini $M$ et al. IFN- $\alpha 1$ gene expression into metastatic murine adenocarcinoma (TS/A) results in $\mathrm{CD}^{+} \mathrm{T}$ cell-mediated tumor rejection and development of antitumor immunity. Comparative studies with IFN-gamma producing TS/A cells. Immunol 1994; 153: 4604-4615.

7 Kaido T et al. IFN- $\alpha 1$ gene transfection completely abolishes the tumorigenicity of murine B16 melanoma cells in allogeneic DBA/2 mice and decreases their tumorigenicity in syngeneic C57BL/6 mice. Int J Cancer 1995; 60: 221-229.

8 Sarkar S et al. Injection of irradiated B16 melanoma genetically modified to secrete IFN- $\alpha$ causes regression of an established tumor. Int J Oncol 1995; 7: 17-24.

9 Santodonato L et al. Cure of mice with established metastatic friend leukemia cell tumors by a combined therapy with tumor cells expressing both interferon-a1 and herpes simplex thymidine kinase followed by gancyclovir. Hum Gene Ther 1996; 7: 1-10.

10 Ferbas J et al. $\mathrm{CD}^{+}$blood dendritic cells are potent producers of IFN- $\alpha$ in response to in vitro HIV-1 infection. J Immunol 1994; 152: 4649-4662.

11 Fitzgerald-Bocarsly P. Human natural interferon- $\alpha$ producing cells. Pharmac Ther 1993; 60: 39-62.

12 Eloranta M-L, Sandberg K, Alm GV. The interferon- $\alpha$ responses of mice to herpes simplex virus studied at the blood and tissue level in vitro and in vivo. Scand J Immunol 1996; 43: 355-360.

13 Svensson $\mathrm{H}$ et al. The cell surface phenotype of human natural interferon- $\alpha$ producing cells as determined by flow cytometry. Scand I Immunol 1996; 44: 164-172.

14 Belardelli F. Role of interferons and other cytokines in the regulation of the immune response. APMIS 1995; 103: 161-179.

15 Rogge L et al. Selective expression of an interleukin-12 receptor component by human T helper cells. J Exp Med 1997; 185: 825-831.

16 Tough DF, Borrow P, Sprent J. Induction of bystander T cell proliferation by viruses and type I interferon in vivo. Science 1996; 272: 1947-1950.

17 Belldegrun A et al. Human renal carcinoma line transfected with interleukin-2 and/or interferon $\alpha$ gene(s): implications for live cancer vaccines. I Natl Cancer Inst 1993; 85: 207-216.

18 Hathorn RW et al. In vitro modulation of the invasive and metastatic potentials of human renal cell carcinoma by interleukin-2 and/or interferon $\alpha$ gene transfer. Cancer 1994; 74: 1904-1911.

19 Gutterman JU. Cytokine therapeutics: lessons from interferon $\alpha$. Proc Natl Acad Sci USA 1994; 91: 1198-1205. 
20 Parmiani G, Colombo MP, Melani C, Arienti F. Cytokine genetransduction in the immunotherapy of cancer. Adv Pharmacol (in press).

21 Tahara $\mathrm{H}$ et al. Fibroblasts genetically engineered to secrete interleukin-12 can suppress tumor growth and induce antitumor immunity to a murine melanoma in vivo. Cancer Res 1994; 54: 182-189.

22 Zitvogel L et al. Cancer immunotherapy of established tumors with interleukin-12 (IL-12): effective delivery by genetically engineered fibroblasts. J Immunol 1995; 155: 1393-1403.

23 Tahara $\mathrm{H}$ et al. Clinical protocol: IL-12 gene therapy using direct injections of tumors with genetically engineered autologous fibroblasts. Hum Gene Ther 1995; 6: 1607-1624

24 Elder EM, Lotze MT, Whiteside TL. Successful culture and selection of cytokine gene-modified human dermal fibroblasts for the biological therapy of patients with cancer. Hum Gene Ther 1996; 7: 479-487.

25 Yang N-S, Sun WH. Gene gun and other non-viral approaches for cancer gene therapy. Nature Med 1995; 1: 481-483.

26 Rakhmilevich AL et al. Gene gun-mediated skin transfection with interleukin-12 gene results in regression of established primary and metastatic murine tumors. Proc Natl Acad Sci USA 1996; 93: 6291-6296.

27 Mahvi DM et al. Particle-mediated gene transfer of granulocytemacrophage colony-stimulating factor cDNA to tumor cells implications for a clinically relevant tumor vaccine. Hum Gene Ther 1996; 7: 1535-1543.

28 Albertini MR et al. Dual expression of human leukocyte antigen molecules and the B7-1 costimulatory molecule (CD80) on human melanoma cells after particle-mediated gene transfer. Cancer Gene Ther 1996; 3: 192-201.

29 Danos O, Mulligan R. Safe and efficient generation of recombinant retroviruses with amphotropic and ecotropic host ranges. Proc Natl Acad Sci USA 1988; 85: 6460-6464.

30 Pear W, Nolan G, Scott M, Baltimore D. Production of high-titer helper-free retroviruses by transient transfection. Proc Natl Acad Sci USA 1993; 90: 8392-8396.
31 Zatloukal JM et al. Elicitation of a systemic and protective antimelanoma immune response by an IL-2-based vaccine. J Immunol 1995; 154: 3406-3419.

32 Leimig $\mathrm{T}$ et al. High-efficiency transduction of freshly isolated human tumor cells using adenoviral interleukin-2 vectors. Hum Gene Ther 1996; 7: 1233-1239.

33 Zhang JF et al. Treatment of a human breast cancer xenograft with an adenovirus vector containing an interferon gene results in rapid regression due to viral oncolysis and gene therapy. Proc Natl Acad Sci USA 1996; 93: 4513-4518.

34 Zhang JF et al. Gene therapy with an adeno-associated virus carrying an interferon gene results in tumor growth suppression and regression. Cancer Gene Ther 1996; 3: 31-38.

35 Toloza EM et al. In vivo cancer gene therapy with a recombinant interleukin-2 adenovirus vector. Cancer Gene Ther 1996; 3: 11-17.

$36 \mathrm{Ju}$ DW, Cao X, Acres B. Intratumoral injection of GM-CSF gene encoded recombinant vaccinia virus elicits potent antitumor response in a murine melanoma model. Cancer Gene Ther 1997, 4: 139-144.

37 Caruso $\mathrm{M}$ et al. Adenovirus-mediated interleukin-12 gene therapy for metastatic colon carcinoma. Proc Natl Acad Sci USA 1996 93: $11302-11306$

38 Bramson JL et al. Construction of a double recombinant adenovirus vector expressing a heterodimeric cytokine: in vitro and in vivo production of biologically active interleukin-12. Hum Gene Ther 1996; 7: 333-342.

39 Bramson JL et al. Direct intratumoral injection of an adenovirus expressing interleukin-12 induces regression and long-lasting immunity that is associated with highly localized expression of interleukin-12. Hum Gene Ther 1996; 7: 1995-2002.

40 Meko JB, Yim JH, Tsung K, Norton JA. High cytokine production and effective antitumor activity of a recombinant vaccinia virus encoding murine interleukin 12. Cancer Res 1996; 55 4765-4770.

41 Zitvogel L et al. Construction and characterization of retroviral vectors expressing biologically active human interleukin 12 . Hum Gene Ther 1994; 5: 1493-1506. 